\title{
AC loss simulation in a HTS 3-Phase 1 MVA transformer using $H$ formulation
}

\author{
Wenjuan Song ${ }^{1,2}$, Zhenan Jiang, ${ }^{*, 2}$, Xingyou Zhang ${ }^{3}$, Mike Staines ${ }^{2}$, Rodney A. Badcock², Jin Fang ${ }^{1}$, \\ Yusuke Sogabe ${ }^{4}$, Naoyuki Amemiya ${ }^{4}$ \\ ${ }^{1}$ School of Electrical Engineering, Beijing Jiaotong University, Beijing 100044, China; \\ ${ }^{2}$ Robinson Research Institute, Victoria University of Wellington, 69 Gracefield Road, PO Box 33-436, \\ Lower Hutt 5046, New Zealand; \\ ${ }^{3}$ Callaghan Innovation, 69 Gracefield Road, PO Box 31-310, Lower Hutt 5040, New Zealand \\ ${ }^{4}$ Department of Electrical Engineering, Graduate School of Engineering, Kyoto University, Kyoto 615-8510, Japan \\ Email: Zhenan.Jiang@vuw.ac.nz.
}

\begin{abstract}
One of critical issues for HTS transformers is achieving sufficiently low AC loss in the windings. Therefore, accurate prediction of AC loss is critical for the HTS transformer applications. In this work, we present AC loss simulation results employing the $H$-formulation for a 1 MVA 3-Phase HTS transformer. The high voltage (HV) windings are composed of 24 double pancakes per phase wound with $4 \mathrm{~mm}$ - wide YBCO wire. Each double pancake coil has $381 / 4$ turns. The low voltage (LV) windings are 20 turn single-layer solenoid windings wound with 15/5 (15 strands of $5 \mathrm{~mm}$ width) Roebel cable per phase. The numerical method was first verified by comparing the numerical and experimental AC loss results for two coil assemblies composed of two and six double pancake coils (DPCs). The numerical AC loss calculated for the transformer was compared with the measured $\mathrm{AC}$ loss as well as the numerical result obtained using the minimum magnetic energy variation (MMEV) method. The numerical AC loss result in this work and experimental result as well as the numerical result using MMEV at the rated current agree to within 20\%. Further simulations were carried out to explore the dependence of the AC loss on the gap between the turns of the LV winding. The minimum AC loss at rated current in the 1 MVA HTS transformer appears when the gap between turns is approximately $2.1 \mathrm{~mm}$ turn gap in the LV winding. This is due to the change of relative heights between the $\mathrm{HV}$ and LV windings which results in optimal radial magnetic field cancellation. The same numerical method can be applied to calculate AC loss in larger rating HTS transformers.
\end{abstract}

Keywords: HTS transformer; AC loss; $H$-formulation; structured mesh; edge element; homogenization method

\section{Introduction}

Large scale HTS (high temperature superconducting) applications, such as generators, transformers, fault current limiters and superconducting magnetic energy storage, are composed of HTS coils/windings with large turn numbers [1-5]. AC loss in HTS windings is one of the key issues, because it adds heat load to the cooling system and hence reduces the efficiency of the devices. Therefore, it is critical to predict the AC loss in these windings with large turn numbers using numerical methods to be able to optimise the design of the windings and cooling system.

Numerical modelling of AC loss for single tapes and stacks composed of large number of conductors has been done by many methods, such as the $H$ formulation $[6,7]$, $A$ - $V$ formulation [8], $T-\Omega$ formulation [9], $T-A$ formulation [10] and MMEV method [11]. The $H$ formulation method is promising with many advantages: small number of variables, direct computation of magnetic field components, easy application of boundary conditions, and automatic satisfaction of continuity of the tangential component of variables [12].

Recently, a HTS 1 MVA 3-Phase transformer was demonstrated by Robinson Research Institute, Victoria University of Wellington, in New Zealand. The high voltage (HV) windings are composed of 24 double pancakes per phase wound with $4 \mathrm{~mm}$-wide YBCO wire with each double pancake coil having 381/4 turns [1]. The low voltage (LV) windings are 20-turn single-layer solenoid windings wound with $15 / 5$ (15 $5 \mathrm{~mm}$ strand)
Roebel cable per phase. AC loss of a single phase of the 1 MVA transformer without ferromagnetic core was measured and calculated using MMEV [13].

In this paper, we presents modelling results for the 1 MVA HTS transformer with approximately one thousand turns in the $\mathrm{HV}$ winding and 20 turn 15/5 Roebel cable solenoid in the LV winding, as well as a stand-alone solenoid coil which has the same geometry as the LV winding, using $H$ formulation, for which there has been no report of simulations using this method for large turn number transformers. A structured rectangular mesh [7], edge element method [6], and homogenization method [14] were used to optimise the simulation accuracy and calculation speed.

The numerical method was first verified with smaller scale HTS windings by comparing the numerical and experimental AC loss results in two coil assemblies composed of a stack of two and six double pancake coils (DPCs) $[15,16]$. The simulated AC loss results for the transformer were then compared with the measured result as well as the one obtained using the MMEV method [13]. We also carried out simulations by changing the gap between turns in the $\mathrm{LV}$ winding to investigate the dependence of the AC loss in the transformer on this parameter. The gap was varied in the range of $1 \mathrm{~mm}-4$ $\mathrm{mm}$. The result can be explained by considering the magnetic field distributions around the LV and the HV windings.

\section{Numerical method}


Calculations were carried out using the $H$ formulation. A combination of structured mesh, edge element [6], and homogenization methods [14] was used. In the following we recap some details of the $H$ formulation and homogenization method. The model was implemented using COMSOL Multiphysics 5.2 and a computer equipped with Intel(R) Core(TM) i5-4570 CPU @3.2GHz and a RAM of $16 \mathrm{~GB}$.

\section{$2.1 H$ formulation}

A 2D axial symmetrical $H$ formulation was applied in the calculation. The variables in the model were defined as $\boldsymbol{H}=\left[H_{r}, H_{z}\right]^{\mathrm{T}}$, where $H_{r}$ and $H_{z}$ are the radial and axial magnetic field components, respectively. The injected or induced current $\boldsymbol{I}$ flows in the $\varnothing$ direction as shown in Fig. 1. The relationship between local electric field $E_{\emptyset}$ and local current density $J_{\emptyset}$ is expressed as, $E_{\emptyset}=\rho J_{\emptyset}$, where $\rho$ is the resistivity of the material.

The Maxwell equations used in the model are expressed as follows,

$$
\begin{gathered}
\boldsymbol{J}=\nabla \times \boldsymbol{H} \\
\nabla \times \boldsymbol{E}=-\frac{\partial \boldsymbol{B}}{\partial t}=-\mu_{0} \mu_{r e} \frac{\partial \boldsymbol{H}}{\partial t}
\end{gathered}
$$

As $\boldsymbol{E}$ has the same direction as $\boldsymbol{J}$, namely $E_{\emptyset}$ only, by substituting Eq. (1) and $E_{\emptyset}=\rho J_{\emptyset}$ into Eq. (2), we can get

$$
\left\{\begin{array}{c}
\mu_{0} \mu_{r e} \frac{\partial H_{r}}{\partial t}-\frac{\partial\left(\rho\left(\frac{\partial H_{z}}{\partial r}-\frac{\partial H_{r}}{\partial z}\right)\right)}{\partial z}=0 \\
\mu_{0} \mu_{r e} \frac{\partial H_{z}}{\partial t}+\frac{1}{r} \frac{\partial\left(r \rho\left(\frac{\partial H_{z}}{\partial r}-\frac{\partial H_{r}}{\partial z}\right)\right)}{\partial r}=0
\end{array}\right.
$$

where $\mu_{0}$ is vacuum permeability and $\mu_{r e}$ is relative permeability with the value of one in this work because there is no magnetic substrate or any other ferromagnetic materials. It is worth noting that different materials have different $\rho$ values. E.g., for air we use $\rho_{\text {air }}=1 \Omega \mathrm{m}$, but for superconductors, we define $\rho_{\mathrm{HTS}}$ based on a power-law for $E$ as a function of $J$ :

$$
\rho_{H T S}=\frac{E_{c}}{J_{c}(B)}\left|\frac{J_{\phi}}{J_{c}(B)}\right|^{(n-1)}
$$

where $J_{\mathrm{c}}(B)$ is the critical current density as a function of magnetic field; $E_{\mathrm{c}}=10^{-4} \mathrm{~V} / \mathrm{m} ; n$ is the power-law exponent of the $E$ - $J$ curve with its value assumed to be 30 in this work. For the $J_{\mathrm{c}}(B)$ relationship, we have used a modified Kim model [17]:

$$
J_{\mathrm{c}}(B)=J_{\mathrm{c} 0}\left(1+\frac{\left|B_{\perp}\right|}{B_{0}}\right)^{-\alpha}
$$

Where $J_{\mathrm{c} 0}$ and $B_{0}$ are constants determined from the measured $E-J$ curve of coated conductors under perpendicular magnetic field, $B_{\perp}$. Table 1 shows the specifications for magnetic field dependence in all simulations in the paper. The details of the two-DPC and six-DPC stacks can be found in Section 3.

Table 1

Magnetic field dependence parameters.

\begin{tabular}{llll}
\hline & $J_{\mathrm{c} 0}\left(\mathrm{~A} / \mathrm{m}^{2}\right)$ & $B_{0}(\mathrm{mT})$ & $\alpha$ \\
Two-DPC stack & $2.6 \times 10^{10}$ & 125 & 1 \\
CWs in six-DPC stack & $2.15 \times 10^{10}$ & 170 & 1 \\
EWs in six-DPC stack & $5.95 \times 10^{10}$ & 150 & 1 \\
LV winding in transformer & $3.55 \times 10^{10}$ & 149 & 0.6 \\
HV winding in transformer & $2.12 \times 10^{10}$ & 149 & 0.6 \\
\hline
\end{tabular}

\subsection{Homogenization method}

The homogenization method was introduced in [14] for simulating AC loss in stacks comprising up to 64 HTS coated conductors. In this paper, we extend it to calculate AC loss in the large-turn-number $\mathrm{HV}$ and $\mathrm{LV}$ windings of the 1 MVA air-core transformer. It is worth noting each turn of Roebel-cable LV winding was modelled as two parallel stacks with a total of either 14 or 16 conductors, carrying the same current in each conductor $[18,19]$. In the model constraints were applied to the current to impose equally distributed current in all parallel conductors [20, 21]. The homogenization method adopts an equivalent anisotropic homogeneous bulk $\mathrm{S}$ for the cross-section of stacks/coils such that the geometrical layout of the internal structures of metallic, substrate layer, and superconducting layer are merged together while keeping its original overall electromagnetic properties. In a tightly piled stack composed of infinitely thin conductors, we have the condition as follows [14],

$$
K(z, t)=\int_{S} J(r, z, t) d r
$$

where $K(z, t)$ is the sheet current density at specific height $z$ in $\mathrm{S} ; J(r, z, t)$ is the current density and $t$ is the specific time during one AC cycle.

Fig. 1 gives the schematics of subdivided sub-blocks. The original coil/stack is composed of $p$ tapes $\mathrm{T}_{1}, \mathrm{~T}_{2}, \mathrm{~T}_{3}$, $\ldots, \mathrm{T}_{p}$. There are $q(q<p)$ sub-blocks $\mathrm{S}_{1}, \mathrm{~S}_{2}, \mathrm{~S}_{3}, \ldots, \mathrm{S}_{q}$ in the corresponding homogenized bulk $\mathrm{S}$, carrying current $I_{1}(t), I_{2}(t), I_{3}(t), \ldots, I_{q}(t)$, and having the heights of $h_{1}, h_{2}, h_{3}$, $\ldots, h_{q}$, respectively. Then the current constraints can be expressed as,

$$
K(z, t)=\frac{I_{1}(t)}{h_{1}}=\frac{I_{2}(t)}{h_{2}}=\frac{I_{3}(t)}{h_{3}}=\ldots=\frac{I_{q}(t)}{h_{q}}
$$

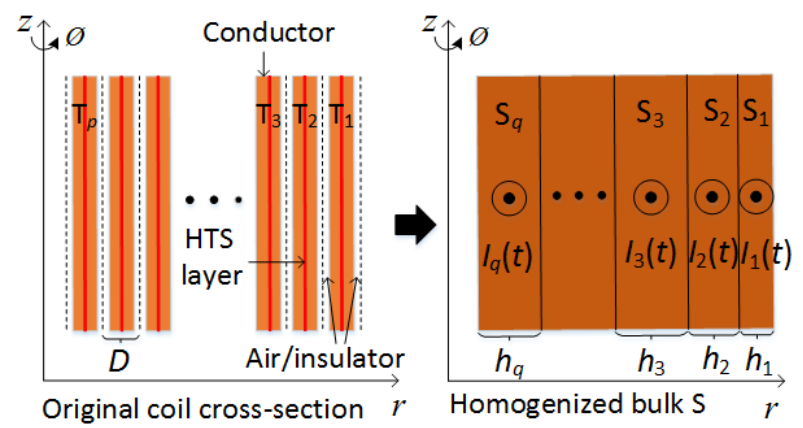

Fig. 1 Schematic of the homogenized bulk. 
For the homogenous bulk, the equivalent engineering critical current density, $J_{c, \text { eng, }}$, is defined as,

$$
J_{\mathrm{c}, \text { eng }}=J_{\mathrm{c}} f_{\mathrm{HTS}}
$$

where $f_{\text {HTS }}$ is the volume fraction of superconductor, the ratio of the thickness of the superconducting layer to the tape thickness D, as shown in Fig. 1.

\section{Validation of the simulation method}

The simulation method was validated by comparing the numerical and experimental AC loss values in the twoDPC and six-DPC stacks.

\subsection{The two-DPC stack}

Table 2

YBCO wire specifications.

\begin{tabular}{ll}
\hline Wire type & YBCO \\
Manufacturer & SuperPower \\
Critical current (A) & 104 \\
Width (mm) & 4 \\
Thickness (mm) & 0.1 \\
Substrate & Hastelloy \\
\hline
\end{tabular}

The two-DPC assembly is wound with SuperPower SCS4050 wire. The specifications of the wire are shown in Table 2. Each DPC has 40 turns, with a $1 \mathrm{~mm}$ gap between the two pancakes of the DPC to give a total height of $9 \mathrm{~mm}$. The inner and outer diameter of the coil is $60 \mathrm{~mm}$ and 73 $\mathrm{mm}$, respectively. The gap between the two DPCs is 0.2 $\mathrm{mm}$.

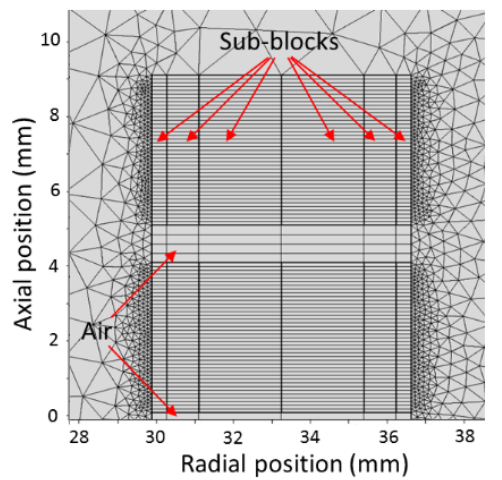

Fig. 2 Structured meshes for the two DPC stack (upper half model).

The structured meshes for the upper half model of the two-DPC stack is shown in Fig. 2. Each pancake was divided into six sub-blocks in the radial direction and 40 elements along the axial direction. The DOF (degrees of freedom) was reduced substantially compared to trianglebased traditional meshes.

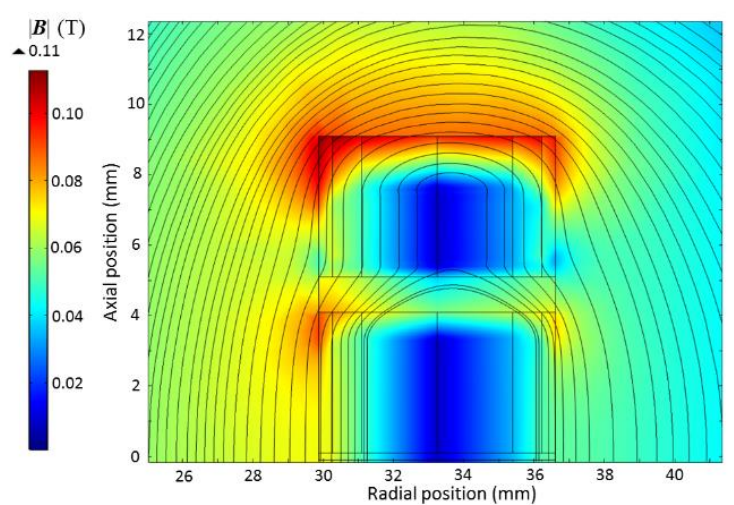

Fig. 3 Magnetic flux density distribution at the peak current $\left(I_{\mathrm{m}}=36.4 \mathrm{~A}\right)$. A half model is shown.

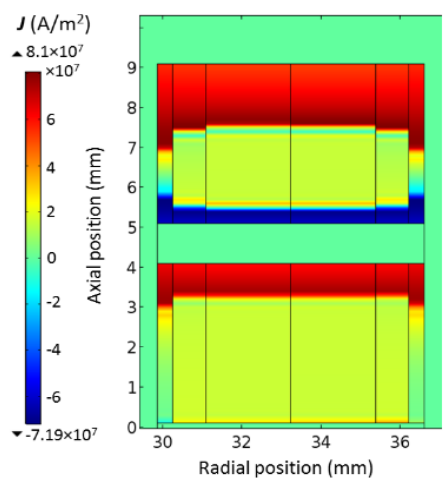

Fig. 4 Current density distribution at the peak current $\left(I_{\mathrm{m}}=36.4 \mathrm{~A}\right)$.

Fig. 3 and Fig. 4 show the current density distribution and magnetic flux density distribution of the two-DPC stack, respectively, at the peak current, $I_{\mathrm{m}}=36.4 \mathrm{~A}$. The magnetic and current density distributions mimic the results shown in a previous report [22]. In Fig. 3, we observe magnetic field penetration in the air gap between the two pancake coils in each DPC. At the bottom of the top pancake, there is magnetization current (shielding current) flowing in the opposite direction to the coil current, shielding the radial magnetic field in the end part of the DPCs as shown in Fig. 4. Current with negative sign does not appear in the central two pancakes [22, 23].

Fig. 5 shows the calculated AC loss in the two-DPC assembly compared with measured results. The measurement was carried out at $24.63 \mathrm{~Hz}$ [24]. Calculation accurately reproduces the measured values but the loss is underestimated by $16 \%$ at $25.5 \mathrm{~A}$, and by $4 \%$ at $46.8 \mathrm{~A}$. 


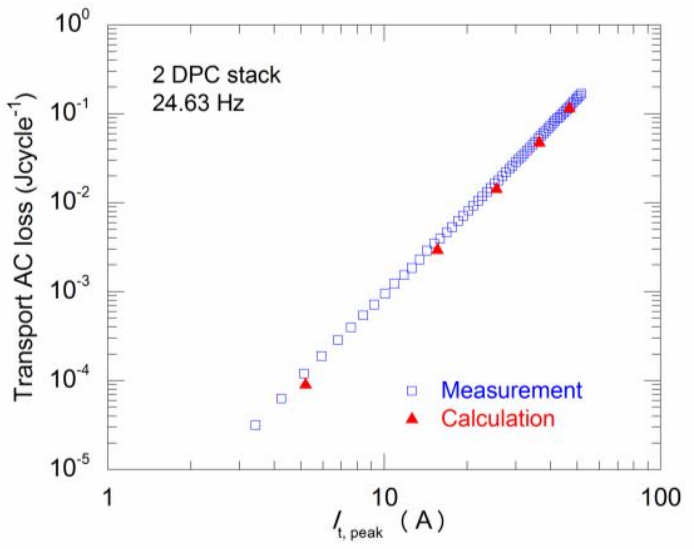

Fig. 5 Calculated AC loss in the two-DPC assembly compared with measured results.

\subsection{The six-DPC stack}

The six-DPC assembly had a REBCO/REBCO hybrid structure [16]. It comprised four DPCs using SuperPower wire (SCS4050) for its central winding (CW) and two DPCs as two ending windings (EWs) using SuNam wire (HCN04200). The parameters used in the modelling for the wires are shown in Table 3.

Table 3

REBCO wire specifications.

\begin{tabular}{lll}
\hline Wire type & REBCO & REBCO \\
Manufacturer & SuNam & SuperPower \\
Critical current (A) & 238 & 86 \\
Width (mm) & 4 & 4 \\
Thickness $(\mathrm{mm})$ & 0.1 & 0.1 \\
Substrate & Hastelloy & Hastelloy \\
\hline
\end{tabular}

Fig. 6 shows the magnetic flux density distribution around the upper half of the assembly at $I_{\mathrm{m}}=40 \mathrm{~A}$. There are strong radial magnetic field components in the end DPCs. Magnetic field penetrates all gaps except the central gap.

Fig. 7 displays the normalized current density distribution, $J / J_{\mathrm{c}}$ at $I_{\mathrm{m}}=40$ A. Current flowing in the reverse direction to the coil current is observed at the inner edges of all pancake coils except the very central two pancakes. This explains the penetration of magnetic field in the gaps between the pancake coils. The extent of the reversed current is greater in the end DPCs of the $\mathrm{CW}$ than in the two EWs. This is due to the use of different wires in the $\mathrm{CW}$ and EWs, i.e., high $I_{\mathrm{c}}$ SuNam wires were used in EWs and low $I_{\mathrm{c}}$ SuperPower wires in the CW.

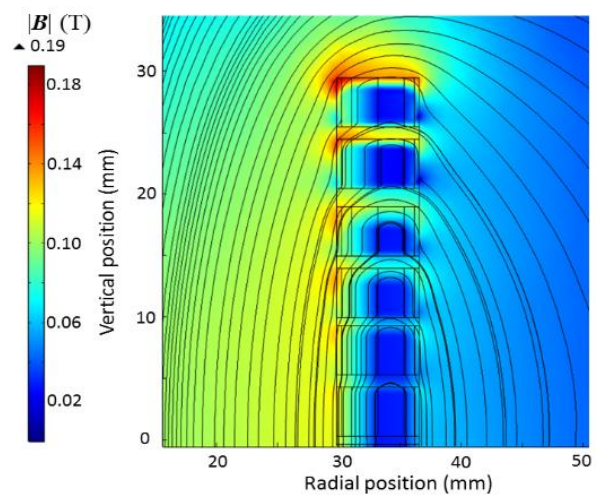

Fig. 6 Magnetic flux density distribution at the peak current $\left(I_{\mathrm{m}}=40 \mathrm{~A}\right)$. The upper half of the assembly only is shown.

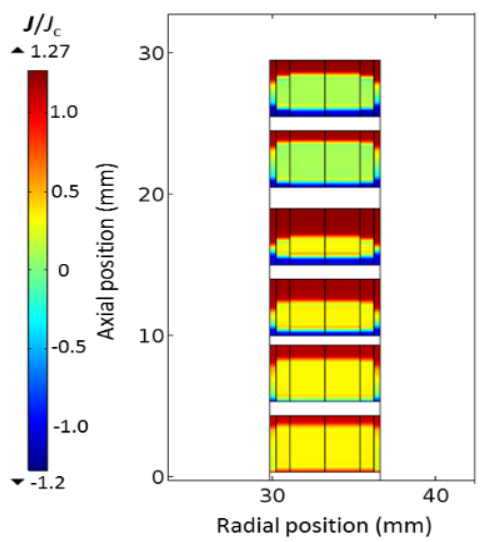

Fig. 7 Current density distribution $J / J_{\mathrm{c}}$ at the peak current $\left(I_{\mathrm{m}}=40 \mathrm{~A}\right)$.

The calculated AC loss in the six-DPC assembly is shown in Fig. 8 and compared with the values measured at $43.96 \mathrm{~Hz}$. The calculated AC loss values are in good agreement with the measured ones. The disagreement between the calculated and measured at $I_{\mathrm{m}}=21 \mathrm{~A}\left(I_{\mathrm{m}} / I_{\mathrm{c}} \approx\right.$ 0.5 ) is only $1.7 \%$.

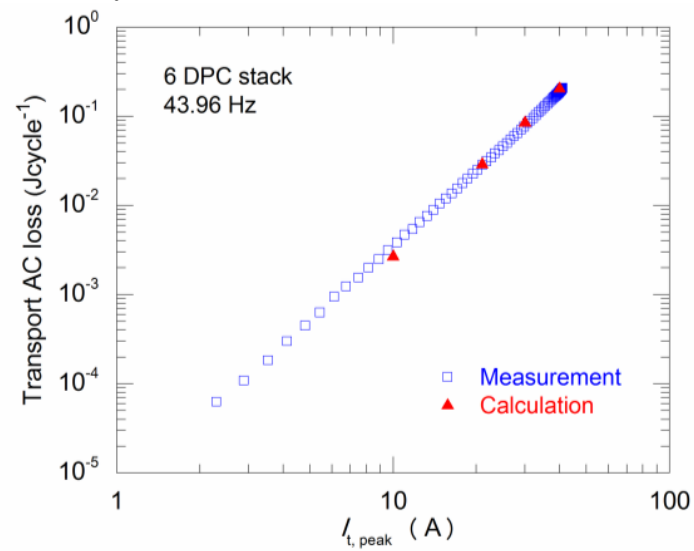

Fig. 8 Calculated AC loss values in the six-DPC assembly compared with measured results.

\section{Results and discussion}

\subsection{MVA transformer}

The parameters for simulating the 1 MVA transformer are listed in Table 4 [13]. 
Table 4

Parameters in 1 MVA transformer modelling.

\begin{tabular}{lll}
\hline & HV & LV \\
\hline Inner diameter (mm) & 345 & 300 \\
Turn number in axial direction & 48 & 20 \\
Turn number in radial direction & 19 & 1 \\
Total number of turns & 912 & 20 \\
Conductor width (mm) & 4 & 12.1 \\
Conductor thickness (mm) & 0.22 & $0.7(/ 0.8)$ \\
Axial gap between turns (mm) & 2.13 & 2.1 \\
Roebel strand number & - & 15 \\
Strand width (mm) & - & 5 \\
Gap between Roebel stacks (mm) & - & 2.1 \\
Constant $I_{\mathrm{c}}$ used in the model (A) & 118.7 & 2226 \\
Rated current amplitude (A) & 42.9 & 1964 \\
\hline
\end{tabular}

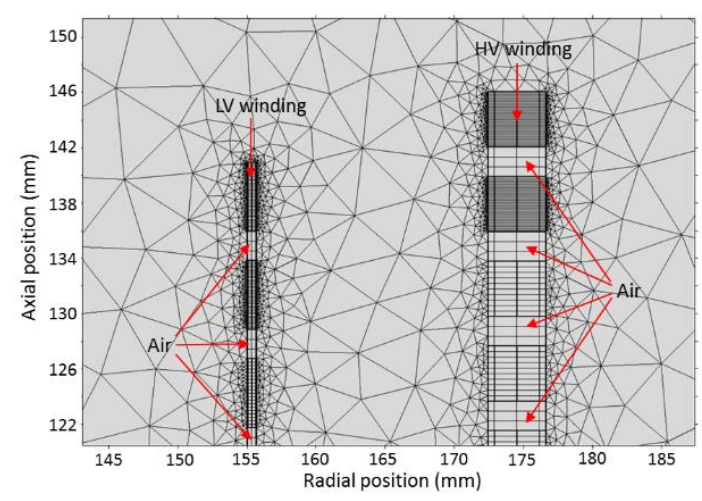

Fig. 9 Meshes for 1 MVA transformer.

Fig. 9 shows the meshes for the upper ends of the 1 MVA transformer. Finer meshes were introduced in the axial direction for the end part of both $\mathrm{LV}$ and $\mathrm{HV}$ windings and coarser meshes were used in the middle part of the windings. This was motivated by the fact that, due to larger radial magnetic components, a larger portion of AC loss is generated in the end part of coil windings, and less AC loss is generated in the middle part. 40 elements were used for the end part, and 20 and 10 elements for middle turns of the $\mathrm{LV}$ and $\mathrm{HV}$ windings, respectively.

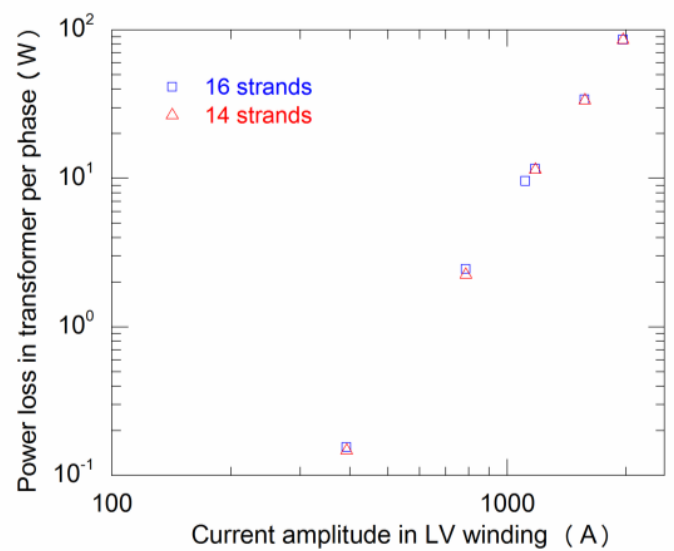

Fig. 10 Loss comparison in 1 MVA transformer model using 16 strands or 14 strands considering constant $J_{\text {c. }}$.

Fig. 10 compares the calculated AC loss values in the 1 MVA transformer with its LV winding modelled with 16 and 14 Roebel strands to avoid the complexity of modelling a Roebel cable with an unequal number of strands in each parallel stack. A constant $J_{\mathrm{c}}$ value was used in the calculation, using measured $I_{\mathrm{c}}$ values of $\mathrm{HV}$ and $\mathrm{LV}$ windings divided by the cross-section area of the superconductor in the wire/Roebel cable. The $J_{\mathrm{c}}$ values for the two cases were adjusted accordingly reflecting actual strand number. The loss values in the figure are in almost perfect agreement. The AC loss value in the LV winding was obtained by averaging the AC loss values for the 16 and 14 tape cables.

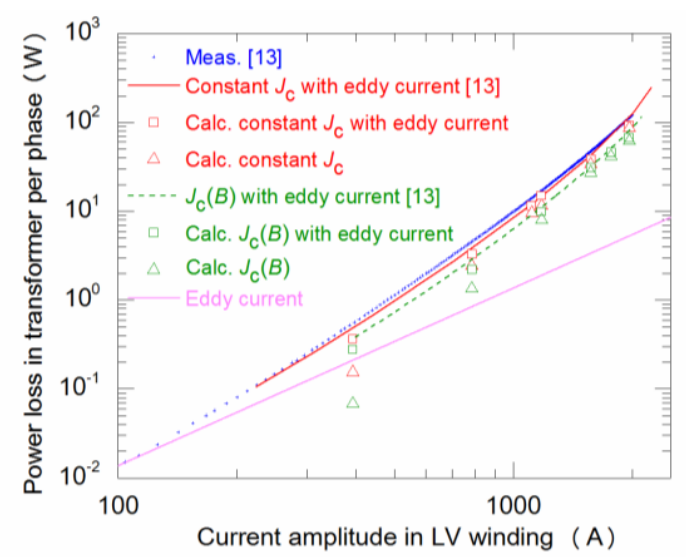

Fig. 11 Calculated AC loss in 1 MVA air-core transformer compared with measured results.

Fig. 11 compares the calculated and measured AC loss values in the 1 MVA air-core transformer assuming shortcircuited secondary winding as done in [13]. The AC loss simulation was carried out assuming either constant $J_{\mathrm{c}}$ or magnetic field dependent $J_{\mathrm{c}}(B)$ for the $\mathrm{LV}$ winding. The $J_{\mathrm{c}}(B)$ characteristic was as defined by Eq. (5) and $J_{\mathrm{c} 0}$ was obtained by dividing the summation of the self-field critical current of the individual Roebel strands by the cross-section area of Roebel cable.

At rated current, $I_{\text {rated }}=1964 \mathrm{~A}$, the measured AC loss value per phase at $50 \mathrm{~Hz}$ and the calculated loss using the MMEV method assuming constant $J_{\mathrm{c}}$, and including the eddy current loss due to the solid copper terminal blocks at the ends of the LV winding in [13] were $112 \mathrm{~W}$ and 110.5 $\mathrm{W}$ respectively. The AC loss at rated current calculated in this paper assuming constant $J_{\mathrm{c}}$ is $91.4 \mathrm{~W}$ including eddy current loss in the terminals and $86.8 \mathrm{~W}$ without eddy current loss. The disagreement between the numerical AC loss result in this work and the experimental result as well as the numerical result using MMEV at rated current are both less than $19 \%$. The calculated AC loss value incorporating field-dependent $J_{\mathrm{c}}(B)$ and eddy current loss in [13] is $81.2 \mathrm{~W}$, and the value in this work is $67.2 \mathrm{~W}$. The disagreement between the two computational results is $17 \%$.

Table 5

Computation time for 1 MVA transformer and stand-alone solenoid.

\begin{tabular}{lll}
\hline$I_{\mathrm{m}} / I_{\mathrm{c}}$ & Time for transformer $(\mathrm{h})$ & Time for solenoid $(\mathrm{h})$ \\
\hline 0.2 & 5.57 & 5.21 \\
\hline 0.5 & 6.06 & 5.68 \\
\hline 0.7 & 6.42 & 5.91 \\
\hline 0.9 & 6.98 & 6.54 \\
\hline 0.9999 & 7.12 & 6.66 \\
\hline
\end{tabular}


Table 5 lists simulation times for a single current amplitude for the transformer and stand-alone solenoid, respectively. The transformer contains additional $\mathrm{HV}$ winding geometry compared to stand-alone solenoid, while it takes nearly similar time to finish one cycle of computation.

\subsection{Stand-alone solenoid wound with Roebel cable}

Fig. 12 compares the calculated AC loss values of the LV winding in the 1 MVA air-core transformer and a stand-alone solenoid coil which shares the same geometrical and electrical parameters as the LV winding. $\mathrm{AC}$ loss in the LV winding is reduced when it is in the shorted-output transformer configuration with balanced current flowing in the HV winding compared with that of the stand-alone solenoid coil. AC loss values in the standalone solenoid are 4 times and 3.92 times that of the LV winding in the transformer configuration at rated current and at $80 \%$ of rated current, respectively. The substantial decrease in AC loss in the $\mathrm{LV}$ winding compared to the stand-alone solenoid is due to the non-inductive nature of the transformer winding [13].

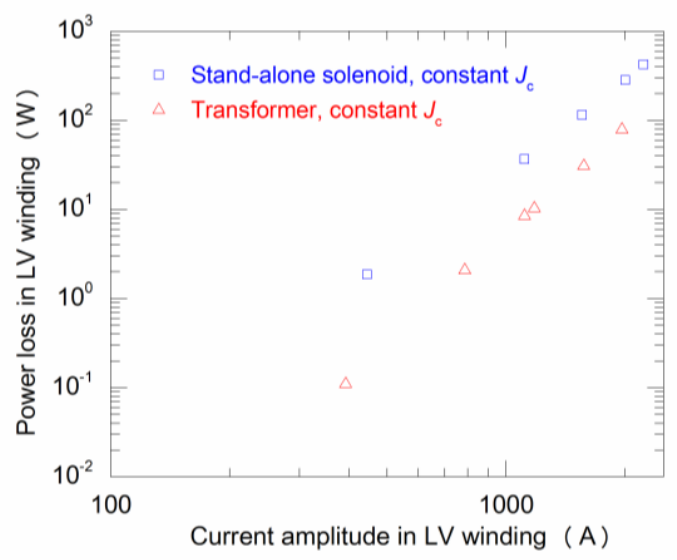

Fig. 12 Calculated loss of LV winding in 1 MVA air-core transformer and a stand-alone solenoid coil.

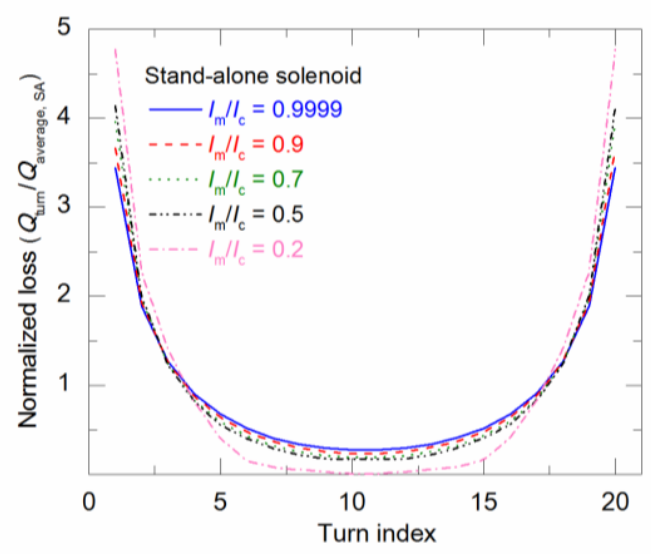

Fig. 13 Normalized loss distribution in each turn of the stand-alone Roebel-cable solenoid. (Roebel cable was regarded as two parallel stacks). Here, $Q_{\text {turn }}$ is the loss value per turn and $Q_{\text {average, SA }}$ is the averaged loss value per turn in stand-alone solenoid. $I_{\mathrm{m}}$ is current amplitude and $I_{\mathrm{c}}$ is critical current, $2226 \mathrm{~A}$.

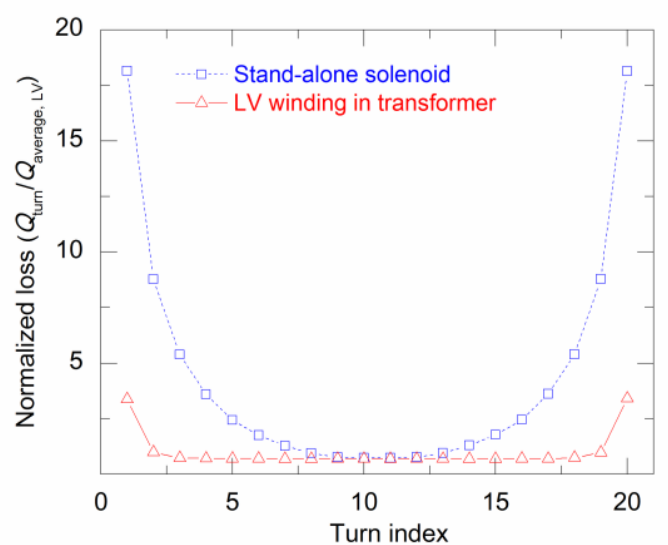

Fig. 14 Normalized loss distribution in each turn of LV winding and compared with that of the stand-alone solenoid (Calculations for $I_{\mathrm{m}} / I_{\mathrm{c}}=$ 0.5 and constant $J_{\mathrm{c}}$ ). Here, $Q_{\text {average, } \mathrm{LV}}$ is the averaged loss value per turn in the $\mathrm{LV}$ winding of the transformer.

The loss distribution in each turn of the stand-alone Roebel-cable solenoid normalized by the averaged AC loss value per turn, $Q_{\text {average, SA, is shown in Fig. 13. Unequal loss }}$ distribution is observed, with normalized AC loss values in end turns much larger than those in the central turns. For $I_{\mathrm{m}} / I_{\mathrm{c}}$ values $0.2,0.5,0.7,0.9$, and 0.9999 , the loss in the end turn is respectively $4.77,4.13,3.96,3.66$, and 3.44 times the average $Q_{\text {average, SA. }}$.

Fig. 14 shows the distribution of the loss in each turn of the $\mathrm{LV}$ winding and the stand-alone solenoid, at $I_{\mathrm{m}} / I_{\mathrm{c}}=0.5$, normalized by the averaged AC loss value per turn in the

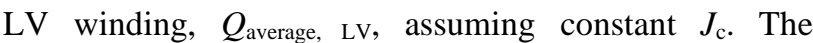
normalized losses are distributed much more homogeneously in the transformer configuration compared to the stand-alone solenoid. Fig. 15 presents magnetic flux distributions in the upper end turns of the transformer winding and the stand-alone solenoid, at $I_{\mathrm{m}} / I_{\mathrm{c}}=0.5$, assuming constant $J_{\mathrm{c}}$. The radial magnetic field in the end turns of the LV winding of the transformer are reduced compared to that in the stand-alone solenoid due to magnetic field cancellation by the LV and $\mathrm{HV}$ windings in the transformer. This explains why the AC loss values in the stand-alone solenoid are much larger than those in the LV winding. 


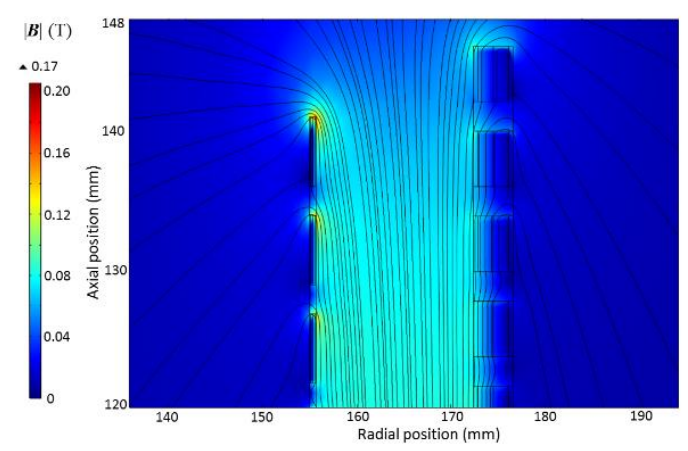

(a)

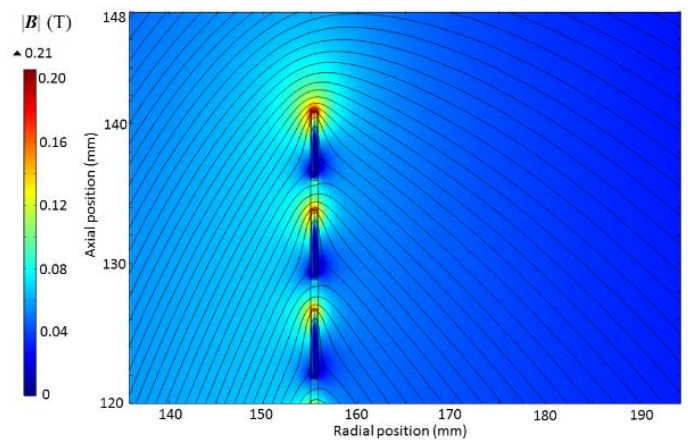

(b)

Fig. 15 Magnetic flux distribution (a) transformer regime (b) stand-alone solenoid regime (Calculations for $I_{\mathrm{m}} / I_{\mathrm{c}}=0.5$ and constant $J_{\mathrm{c}}$ ).

\subsection{AC loss dependence on turn spacing in LV winding}

Fig. 16 shows the dependence of the AC loss of the 1 MVA transformer on the turn spacing in the LV winding, $d_{\mathrm{ts}}$, with $d_{\mathrm{ts}}$ values set at $1 \mathrm{~mm}, 2.1 \mathrm{~mm}, 3 \mathrm{~mm}$, and $4 \mathrm{~mm}$. The dependence of the AC loss of the LV winding equivalent stand-alone solenoid on turn spacing is also shown in the figure. Minimum AC loss of the transformer occurs when $d_{\mathrm{ts}} \approx 2.1 \mathrm{~mm}$ at the rated current, and is $76 \%$, $93 \%$, and $76 \%$ of the values when $d_{\mathrm{ts}}$ is set at $1 \mathrm{~mm}, 3 \mathrm{~mm}$, and $4 \mathrm{~mm}$, respectively. Similar AC loss behaviour is observed when the current amplitude is smaller. For the stand-alone solenoid, the AC loss value decreases monotonically as $d_{\mathrm{ts}}$ increases.

The appearance of minimum AC loss in the transformer might be due to the change of relative heights between the $\mathrm{HV}$ and LV windings which could result in optimal radial magnetic field cancellation. E.g. the half-height of the LV winding is $10.2 \mathrm{~mm}$ shorter than that of the $\mathrm{HV}$ winding when $d_{\mathrm{ts}}=2.1 \mathrm{~mm}$, while it is, $31.1 \mathrm{~mm}$ shorter, $6.9 \mathrm{~mm}$ taller, and $25.9 \mathrm{~mm}$ taller than that of $\mathrm{HV}$ winding when setting $d_{\mathrm{ts}}$ values at $1 \mathrm{~mm}, 3 \mathrm{~mm}$, and $4 \mathrm{~mm}$, respectively.

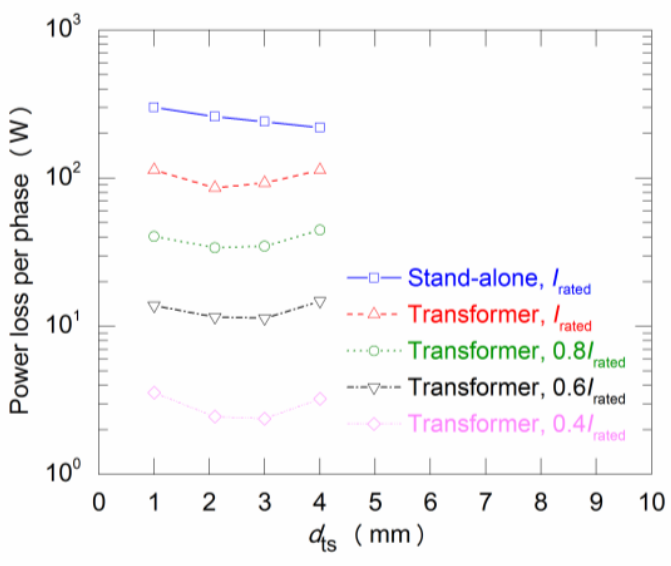

Fig. 16 Loss dependency of the 1 MVA transformer and stand-alone solenoid on turn spacing $d_{\mathrm{ts}}$.

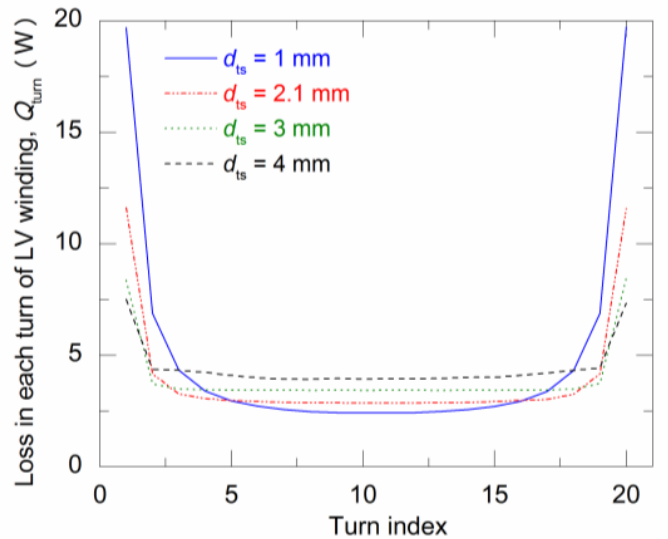

Fig. 17 Loss distribution dependency of LV winding on the turn spacing $d_{\mathrm{ts}}$ at rated current.

Fig. 17 compares the distribution of loss in the LV winding plotted as a function of turn index for different $d_{\mathrm{t}}$ values at rated current. When $d_{\mathrm{ts}}=1 \mathrm{~mm}, \mathrm{AC}$ loss in the end turns is about 8.2 times that in the middle turns, while for $d_{\mathrm{ts}}=4 \mathrm{~mm}$ all turns have similar except the end turn which has less than twice the loss of the other turns. The smaller turn gap produces a larger radial magnetic field component at the end turns, and the larger turn gap results in reduced cancellation of the radial magnetic field component in the middle turns [25].

Fig. 18 illustrates the radial magnetic field distribution in the end turns and the central turns of the $\mathrm{LV}$ winding as $d_{\mathrm{ts}}$ varies. In the end turns, the radial magnetic field component is greatest when $d_{\mathrm{ts}}=1 \mathrm{~mm}$, while when $d_{\mathrm{ts}}=$ $4 \mathrm{~mm}$ the radial magnetic field component becomes the smallest as shown in Fig. 18(a). In the central turns, the radial magnetic field component becomes the smallest when $d_{\mathrm{ts}}=1 \mathrm{~mm}$, while when $d_{\mathrm{ts}}=4 \mathrm{~mm}$ radial magnetic field component is the largest, as shown in Fig. 18(b). The results support the observation in Fig. 17. 


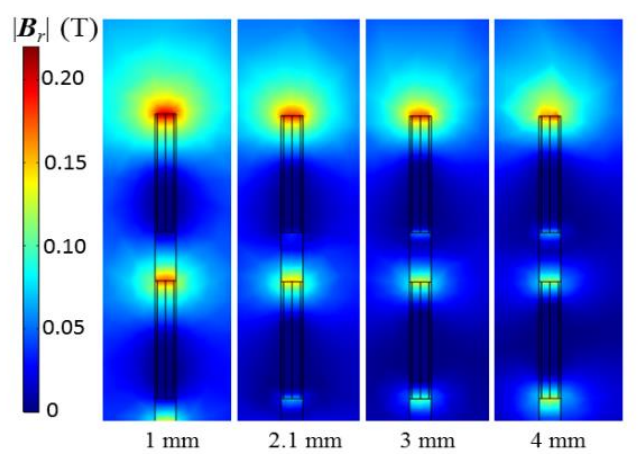

(a)

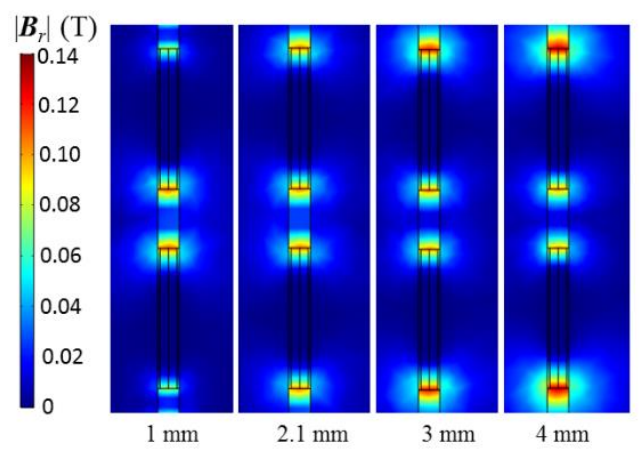

(b)

Fig. 18 Radial magnetic field distribution with gap variation in LV winding, (a) End turn (b) Central turn.

\section{Conclusions}

In this paper, we presents modelling results employing the $H$ formulation with structured mesh, edge element, and homogenization method for a 1 MVA HTS transformer with approximately one thousand turns in the HV winding and with solenoid LV windings, each phase with 20 turns of 15/5 Roebel. In addition we have modelled a standalone solenoid coil with the same geometry as the LV winding.

We successfully reproduced, using the $H$ formulation, characteristic features of the $\mathrm{AC}$ loss and current and magnetic flux distribution for the transformer and standalone solenoid winding observed in [13]. The disagreement, at rated current, between the numerical AC loss result in this work and experimental result as well as the numerical result using the MMEV method is less than $20 \%$ without optimizing meshes.

The minimum AC loss in the 1 MVA HTS transformer appears at approximately $2.1 \mathrm{~mm}$ turn gap in the LV winding at the rated current. The appearance of minimum AC loss in the transformer might be due to the change of relative heights between the $\mathrm{HV}$ and LV windings which could result in optimal radial magnetic field cancellation.

The same numerical method can be applied to calculate AC loss in larger rating HTS transformers.

\section{References}

[1] Glasson ND, Staines MP, Jiang Z, Allpress NS. Verification testing for a 1 MVA 3-phase demonstration transformer using 2G-HTS Roebel cable. IEEE Trans Appl Supercond 2013; 23(3):5500206.

[2] Paul W, Lakner M, Rhyner J, Unternährer P, Baumann T, Chen M, Widenhorn L, Guerig A. Test of 1.2 MVA high-superconducting fault current limiter. Supercond Sci Technol 1997. 10(12):914.

[3] Boenig HJ, Hauer JF. Commissioning tests of the Bonneville Power Administration $30 \mathrm{MJ}$ superconducting magnetic energy storage unit. IEEE Trans Power Apparatus Systems 1985; 2(2):302-12.

[4] Oberly CE, Long L, Rhoads GL, Carr Jr WJ. Ac Loss analysis for superconducting generator armatures wound with subdivided $\mathrm{Y}$ $\mathrm{Ba}-\mathrm{Cu}-\mathrm{O}$ coated tape. Cryogenics 2001; 41(2):117-24.

[5] Vysotsky VS, Fetisov SS, Zubko VV, Zanegin SY, Nosov AA, Ryabov SM, Bykovsky NV, Svalov GG, Volkov EP, Fleishman LS, Dzhafarov EA. Development and Test Results of HTS Windings for Superconducting Transformer With 1 MVA Rated Power. IEEE Trans Appl Supercond 2017; 27(4):1-5.

[6] Brambilla R, Grilli F, and Martini L. Development of an edgeelement model for AC loss computation of high-temperature superconductors. Supercond Sci Technol 2006; 20(1):16-24.

[7] Rodriguez-Zermeno VM, Mijatovic N, Træholt C, Zirngibl T, Seiler E, Abrahamsen AB, Pedersen NF, Sorensen MP. Towards faster FEM simulation of thin film superconductors: a multiscale approach. IEEE Trans Appl Supercond 2011; 21(3): 3273-6.

[8] Barnes G, McCulloch M, Dew-Hughes D. Computer modelling of type II superconductors in applications. Supercond Sci Technol 1999; 12(8):518.

[9] Amemiya N, Murasawa SI, Banno N, Miyamoto K. Numerical modelings of superconducting wires for AC loss calculations. Physica C 1998; 310(1):16-29.

[10] Zhang H, Zhang M, Yuan W. An efficient 3D finite element method model based on the T-A formulation for superconducting coated conductors. Supercond Sci Technol 2016; 30(2):024005.

[11] Pardo E, Gömöry F, Šouc J, Ceballos JM. Current distribution and ac loss for a superconducting rectangular strip with in-phase alternating current and applied field. Supercond Sci Technol 2007; 20(4):351.

[12] Zhang M, Coombs TA. 3D modeling of high-Tc superconductors by finite element software. Supercond Sci Technol 2011; 25(1):015009.

[13] Pardo E, Staines M, Jiang Z, Glasson N. Ac loss modelling and measurement of superconducting transformers with coatedconductor Roebel-cable in low-voltage winding. Supercond Sci Technol 2015; 28(11):114008.

[14] Zermeno VM, Abrahamsen AB, Mijatovic N, Jensen BB, Sørensen MP. Calculation of alternating current losses in stacks and coils made of second generation high temperature superconducting tapes for large scale applications. J Appl Phys 2013; 114(17):173901.

[15] Jiang Z, Long NJ, Staines M, Badcock RA, Bumby CW, Buckley RG, Amemiya N. AC loss measurements in HTS coil assemblies with hybrid coil structures. Supercond Sci Technol 2016; 29(9):095011.

[16] Jiang Z, Staines M, Long NJ, Badcock RA, Bumby CW, Buckley RG, Song W, Amemiya N. AC Loss Measurements in a Hybrid REBCO/BSCCO Coil Assembly. IEEE Trans Appl Supercond 2017; 27(6):5900707.

[17] Kim YB, Hempstead CF, Strnad AR. Critical persistent currents in hard superconductors. Phys Rev Lett 1962; 9(7):306-9.

[18] Jiang Z, Badcock RA, Long NJ, Staines M, Thakur KP, Lakshmi LS, Wright A, Hamilton K, Sidorov GN, Buckley RG, Amemiya N. Transport AC loss characteristics of a nine strand YBCO Roebel cable. Supercond Sci Technol 2010; 23(2):025028.

[19] Terzieva S, Vojenčiak M, Pardo E, Grilli F, Drechsler A, Kling A, Kudymow A, Gömöry F, Goldacker W. Transport and magnetization ac losses of ROEBEL assembled coated conductor cables: measurements and calculations. Supercond Sci Technol 2009; 23(1):014023.

[20] Quéval L, Zermeño VM, Grilli F. Numerical models for ac loss calculation in large-scale applications of HTS coated conductors. Supercond Sci Technol 2016; 29(2):024007. 
[21] Clem JR, Claassen JH, Mawatari Y. AC losses in a finite Z stack using an anisotropic homogeneous-medium approximation. Supercond Sci Technol 2007; 20(12):1130.

[22] Pardo E, Šouc J, Kováč J. AC loss in ReBCO pancake coils and stacks of them: modelling and measurement. Supercond Sci Technol 2012; 25(3):035003.

[23] Amemiya N, Akachi K. Magnetic field generated by shielding current in high Tc superconducting coils for NMR magnets. Supercond Sci Technol 2008; 21(9):095001.

[24] Sogabe Y, Jiang Z, Wimbush SC, Strickland NM, Staines M, Long NJ, and Amemiya N. Ac loss characteristics in REBCO coil assemblies with different geometries and conductors. IEEE Trans Appl Supercond 2018; 28(3):4700105.

[25] Jiang Z, Long NJ, Staines M, Li Q, Slade RA, Amemiya N, Caplin AD. Transport AC loss measurements in single-and two-layer parallel coated conductor arrays with low turn numbers. IEEE Trans Appl Supercond 2012; 22(6):8200306. 